\title{
Study of different automatic irrigation systems
}

\section{A.P. Bowlekar}

Author for Correspondence :

\section{A.P. Bowlekar}

Department of Soil and Water

Engineering, Kelappaji

College of Agricultural

Engineering and Technology

(Kerala Agricultural

University), Tavanur

(Kerala) India

Email: adwaitbowlekar1808@ gmail.com
- ABSTRACT : At the present era, the farmers have been using irrigation techniques in India through manual control, in which farmers irrigate the land at the regular intervals. The farmer has to keep watch on irrigation timetable, which varies according to crop, soil and season. Common methods of water distribution can be enhanced or replaced by using recent technological advances. The Government has invested good amount of money to develop the technology in order to increase the productivity of agriculture. Automatic irrigation system is one of the prudent technologies for more efficient utilization of water resources and applies irrigation water as and when required by the crop. This paper presents the available automatic irrigation system controllers in India, which covers them from different firms manufacturing and selling them to the farmers. All the features of these products are explained shortly.

- KEY WORDS : Automatic, Controller, Irrigation, Sensor

- HOW TO CITE THIS PAPER : Bowlekar, A.P. (2020). Study of different automatic irrigation systems. Internat. J. Agric. Engg., 13(1) : 128-136, DOI: 10.15740/HAS/IJAE/13.1/128-136. Copyright@2020: Hind Agri-Horticultural Society. 